\title{
Trends in Rainfall Patterns over the Tamarabarani Basin in Tamil Nadu, India
}

\author{
C. Sivapragasam $^{a}$, S. Balamurli ${ }^{a}$, M. Deepak ${ }^{a}$, A. Prakhar ${ }^{a}$ and $\underline{\text { N. Muttil }}{ }^{\mathrm{b}}$ \\ ${ }^{a}$ Department of Civil Engineering, Kalasalingam University, TN, India \\ ${ }^{b}$ College of Engineering and Science, Victoria University, Melbourne, Victoria 8001, Australia \\ Email:nitin.muttil@vu.edu.au
}

\begin{abstract}
Rainfall is the key hydro-climatic variable that governs the regional hydrologic cycle and availability of water resources. Recent studies have analysed the changes in rainfall patterns at global as well as regional scales around the world. These studies have also suggested that any analysis of hydro-climatic variables should be performed at the local scale rather than at a large or global scale because the trends and their effects may be different from one location to the other.
\end{abstract}

The Tamarabarani River basin is one of the important basins in Southern Tamil Nadu with rich surface water resources. The basin is mainly agriculture based and people are engaged in the cultivation of various crops like paddy, cotton, sugarcane, groundnut, etc. The Tamarabarani River provides consistent irrigation to a large agricultural area within the basin. The Tamarabarani River and its tributaries have many dams, with reservoirs providing water for irrigation and power generation. The Papanasam and Manimuthar dams located on the western part of the basin are two of the major reservoirs that cater to the water requirements of the district. The basin receives a majority of its rainfall during the northeast monsoon, which is during the months of October, November and December (with November having the maximum rainfalls). Thus, step changes and trends in rainfall for these stations and during the monsoon months would especially be of interest to the farmers, irrigators and water resource managers in the basin.

Since no studies on hydro-climatic trend analysis were found specific to this basin, this study performs a spatiotemporal trend analysis on long-term rainfall records (1971-2000) at 14 measuring stations within the basin. The Mann-Kendall test was used to detect trends and the cumulative summation (CUSUM) technique was used to identify the trend beginning year for monthly rainfall data.

The results of the CUSUM test indicated that the two stations of Papanasam and Dam Camp located in the Western Ghats had a statistically significant step-up change during the late nineteen seventies and early eighties. The trend analysis results indicated that increasing trends were observed (for most of the months) at 3 stations, which are Dam Camp, Papanasam and Cheranmadevi. The Cheranmadevi station exhibited the maximum number of months (seven out of twelve) with statistically significant increasing trends. For Papanasam and Cheranmadevi, the month of November exhibited statistically significant increasing trends. This is encouraging from the irrigation point of view, since these stations are located on the forested western part of the basin, which forms the catchment area for the major reservoirs. Thus, there is an increase in potential for harvesting water from this part of the basin.

On the other hand, it is observed that five stations have exhibited predominantly decreasing trends for most of the months during the past three decades. These stations are Tirunelveli, Manimuthar, Nanguneri, Kovilpatti and Ayyikudi. Most of these stations are located in the central part of the river basin and these areas would need special attention as over exploitation of surface as well as ground water resources in these regions need to be restricted to conserve water for future use.

Keywords: Trend analysis, Rainfall, Mann-Kendall test 


\section{INTRODUCTION}

Rainfall is the key climatic variable that governs the regional hydrologic cycle and availability of water resources. It is also one of the most complex and difficult elements of the hydrological cycle to understand due to the tremendous range of variation over a wide range of scales both in space and time (French et al., 1992). Moreover, factors like climate change and urbanization have also had an impact on the variation in rainfall. Recent studies have stated that any analysis of hydro-climatic variables should be done at the local scale rather than at a large or global scale (Sharma and Shakya, 2006; Barua et al., 2013). This is because, although climate change is a global phenomenon, the trends and their impacts may be different from one location to the other due to the variations of hydro-climatic variables from one region to the other. Therefore, rainfall trend analysis studies have become important, as observational and historical rainfall data are generally used for planning and design of water resource projects.

The present study was focused on rainfall trend analysis at a local scale within the Tamarabarani River basin, rather then at a regional or global scale. Historic rainfall data from multiple rainfall stations were used, as it provides more detailed information on the spatial variability of rainfall trends within the basin. The Tamarabarani River basin was selected for this study as it is one of the important river basins in Tirunelveli district of Tamil Nadu, India. Agriculture plays a vital role in the district's economy and the Tamarabarani River provides consistent irrigation to a large agricultural area. The basin thus has an important contribution towards the sustainable development of the local economy. Therefore, rainfall trend analysis within the basin is important and the outcomes of this study will be highly useful for the planning and management of water resources in the basin.

This paper begins with a brief description of the study area and the dataset used, followed by a description of methodology used in this study. Then the results of the spatio-temporal rainfall trend analysis and discussion are presented, followed by implications of this study for management of water resources within the river basin. Finally, the conclusions drawn from this study are presented.

\section{STUDY AREA AND DATASET USED}

\subsection{The study site}

Tamarabarani River basin is one of the important basins in Southern Tamil Nadu (India) with rich surface water resources. Tamarabarani River originates on the eastern slopes of Western Ghats in the Tirunelveli district of Tamil Nadu and flows into the Gulf of Mannar in the south-eastern coast of India (Figure 1). The basin lies between $8^{\circ} 26^{\prime} 45^{\prime \prime} \mathrm{N}$ and $9^{\circ} 12^{\prime} 00^{\prime \prime} \mathrm{N}$ latitude and $77^{\circ} 09^{\prime} 00^{\prime \prime} \mathrm{E}$ and $78^{\circ} 08^{\prime} 30^{\prime \prime} \mathrm{E}$ longitude.

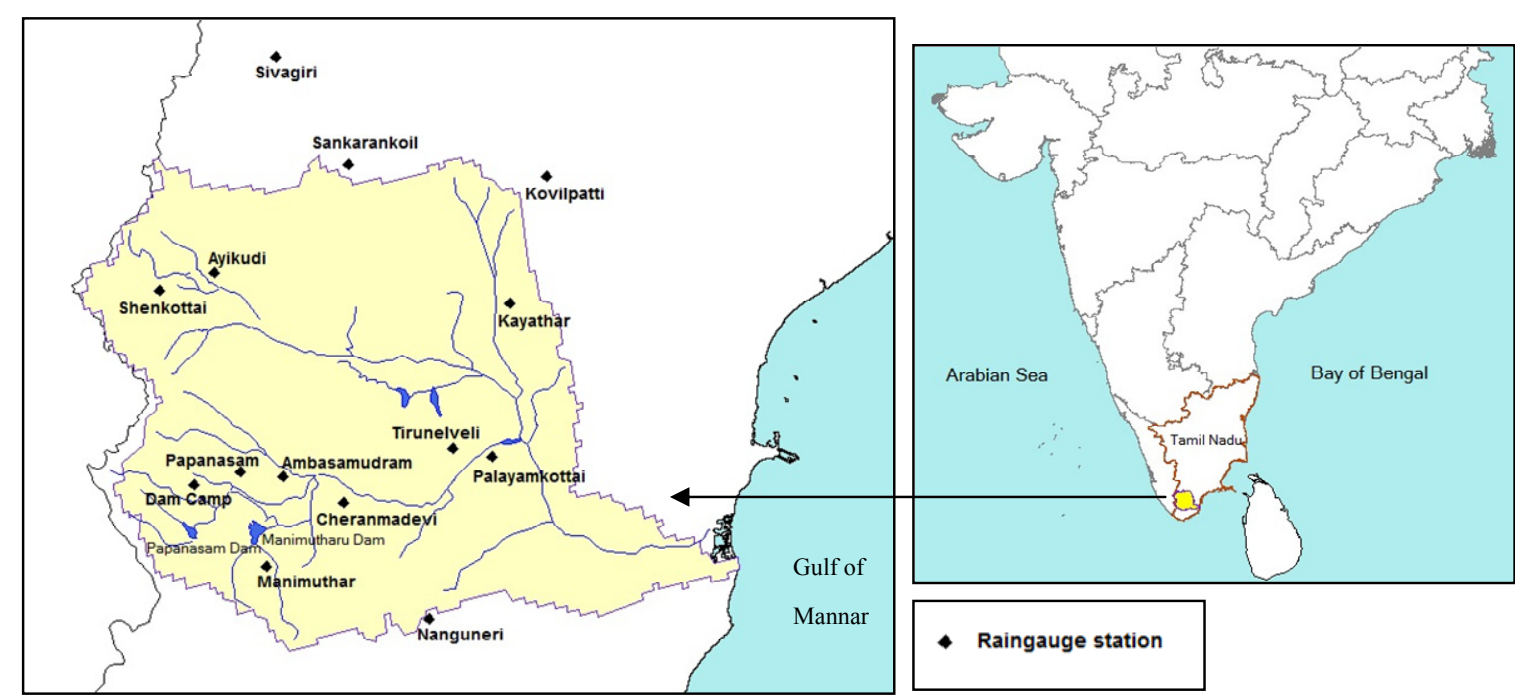

Figure 1. Location of the Tamarabarani River basin and the selected rain gauge stations

The economy of Tirunelveli district is chiefly agrarian in nature and people are engaged in the cultivation of various crops like paddy, cotton, sugarcane, groundnut, etc. The main irrigation sources in the basin are 
reservoirs and irrigation tanks, which are dependent on rainfalls for their replenishment. The Papanasam and Manimuthar dams located on the western part of the basin (as indicated in Figure 1) are two of the major reservoirs that cater to the water requirements of the district.

The district receives the rainfall under the influence of both southwest and northeast monsoons; but the northeast monsoon is the major contributor of the rainfall in the district. The northeast monsoon, which is considered as the major rainy season, is during the months of October, November and December. Hence the rainfall trends especially in these months would be of significance to the farmers and irrigators in the basin.

\subsection{The dataset used}

Based on availability of data, total monthly rainfall data for 30 years (from 1971 - 2000) from 14 rain gauge stations located in and close to the boundary of the basin have been used in this study. The location of the selected 14 rain gauge stations can be seen in Figure 1. The rainfall patterns in the Papanasam, Manimuthar and Dam Camp rain gauge stations would be of significance as these stations are located within the catchment area of the two major reservoirs.

\section{METHODOLOGY}

The CUSUM test and the non-parametric Mann Kendall (MK) test (Mann, 1945) was preformed on the monthly rainfall time series data from the 14 stations within the Tamarabarani River basin to detect the spatial and temporal trends. For each of these two tests, the test statistic was considered to be statistically significant at significance levels of $\alpha=0.01, \alpha=0.05$ and $\alpha=0.1$. A test statistic at significance level of $\alpha>$ 0.1 was not considered to be statistically significant. The CUSUM test was first preformed on each of the time series to check the existence of any statistically significant change in trends and thus identify the trend beginning year. If a statistically significant trend beginning year was found, the dataset after that year was considered for rest of the trend analysis (i.e. for MK test) as the recent trends would be of relevance. If there were no statistically significant trend beginning year in the data, then the complete time series was considered for the trend analysis. Brief mathematical details of the CUSUM test and the MK test are presented in this section.

\subsection{CUSUM test}

As mentioned earlier, the CUSUM test has been used to check the existence of statistically significant change in trends in rainfall time series data and thus to identify the trend beginning year, if it exists (Chowdhury and Beecham, 2010; Yilmaz and Perera, 2013; Barua et al., 2013). The CUSUM test as described in Chowdhury and Beecham (2010) is as follows:

$$
y_{i}=\left(x_{i}+x_{i-1}+x_{i-2}+\cdots x_{n}\right)-i \cdot \bar{x}
$$

where, $y_{i}$ is the computed CUSUM value at any time $i, n$ is the sample size, $x_{i}, \ldots, x_{n}$ is the original rainfall time series, $\bar{x}$ is the average of the total rainfall time series. The plot of $y_{i}$ versus $i$ normally oscillates around the horizontal axis when the original series $\left(x_{i}, \ldots, x_{n}\right)$ is free from statistically significant change in trends. A deviation from the oscillatory pattern suggests a possibility of change in trend, starting from the year of observation of such a change.

\subsection{Mann-Kendal test}

The MK test is a rank-based test for identifying statistically significant trends in a time series and is resistant to the effects of outliers (Hirsch et al., 1993). The MK test is one of the most widely used non-parametric test for detecting trend in hydro-climatic time series (Chowdhury and Beecham, 2010; Yilmaz et al., 2010; Barua et al., 2013). In the $M K$ test, a time series $x_{i}$ was ranked from $i=1,2, \ldots, n-1$ and another time series $x_{j}$ from $\mathrm{j}=2,3, \ldots, \mathrm{n}$, where $\mathrm{n}$ is the number of data points. Each data point in $\mathrm{x}_{\mathrm{i}}$ was then used as a reference point and compared with all other data points in $\mathrm{x}_{\mathrm{j}}(\mathrm{j}>\mathrm{i})$, to obtain the values of the sign for each comparison using Equation (2).

$$
\operatorname{sgn}\left(x_{j}-x_{i}\right)=\left\{\begin{array}{ccc}
+1 & \text { if } & x_{j}>x_{i} \\
0 & \text { if } & x_{j}=x_{i} \\
-1 & \text { if } & x j<x i
\end{array}\right\}
$$

The Kendall's statistic S was then calculated using Equation (3). 
Sivapragasam et al., Trends in Rainfall Patterns over the Tamarabarani Basin in Tamil Nadu, India

$$
S=\sum_{i=1}^{n-1} \sum_{j=i+1}^{n} \operatorname{sgn}\left(x_{j}-x_{i}\right)
$$

where, $\mathrm{n}$ is the number of observed data points. For $\mathrm{n} \geq 10$, the statistic $\mathrm{S}$ is approximately normally distributed with zero mean. The variance of $\mathrm{S}$ was computed using Equation (4).

$$
\operatorname{Var}(S)=\frac{n(n-1)(2 n+5)-\sum_{p=1}^{g} t_{p}\left(t_{p}-1\right)\left(2 t_{p}+5\right)}{18}
$$

where, $g$ is the number of tied groups (a tied group is a set of sample data having the same value) and $t_{p}$ is the number of data points in the $\mathrm{p}^{\text {th }}$ tied group.

The MK test statistic $Z$ was then computed using Equation (5):

$$
Z=\left\{\begin{array}{ccc}
\frac{S-1}{\sqrt{\operatorname{Var}(S)}} & \text { if } & S>0 \\
0 & \text { if } & S=0 \\
\frac{S+1}{\sqrt{\operatorname{Var}(S)}} & \text { if } & S<0
\end{array}\right.
$$

A positive $\mathrm{Z}$ indicates an upward trend while a negative $\mathrm{Z}$ indicates a downward trend.

\section{RESULTS AND DISCUSSION}

In this section, results obtained from the CUSUM analysis for detection of the trend beginning year (or the change point year) and the rainfall trends using MK test for the monthly rainfall time series data are presented. As discussed earlier, the trends are calculated on for the time period after the trend beginning or change point year. In case there are no statistically significant change point year, the trends are calculated for the complete 30 year period.

\subsection{Change point analysis results}

The step change analysis results for the 14 stations are presented in Table 1 . In this table, the step-up changes are shaded.

Table 1. Statistically significant step changes for individual months (shaded values are step-up changes)

\begin{tabular}{|c|c|c|c|c|c|c|c|c|c|c|c|c|c|}
\hline $\begin{array}{c}\text { S. } \\
\text { No. }\end{array}$ & $\begin{array}{c}\text { Raingauge } \\
\text { station name }\end{array}$ & Jan & Feb & Mar & Apr & May & Jun & Jul & Aug & Sep & Oct & Nov & Dec \\
\hline $\mathbf{1}$ & Ambasamudram & 1983 & - & - & - & - & - & - & - & - & - & 1991 & - \\
\hline $\mathbf{2}$ & Ayikudi & 1983 & - & 1991 & - & 1982 & - & 1984 & 1990 & 1989 & - & - & - \\
\hline $\mathbf{3}$ & Cheranmadevi & 1983 & - & - & 1983 & - & 1982 & - & 1993 & - & - & - & - \\
\hline $\mathbf{4}$ & Dam Camp & 1993 & - & - & 1979 & 1979 & 1979 & 1979 & 1979 & 1982 & 1980 & 1981 & 1979 \\
\hline $\mathbf{5}$ & Kayathar & 1989 & - & - & - & - & 1997 & - & - & - & - & 1990 & - \\
\hline $\mathbf{6}$ & Kovilpatti & 1983 & - & - & - & - & - & - & - & - & - & - & - \\
\hline $\mathbf{7}$ & Manimuthar & - & - & - & - & 1981 & - & - & 1981 & 1985 & - & - & - \\
\hline $\mathbf{8}$ & Nanguneri & 1989 & - & 1991 & - & - & - & - & - & - & - & - & - \\
\hline $\mathbf{9}$ & Palayamkottai & 1983 & - & - & - & - & - & - & - & - & - & - & - \\
\hline $\mathbf{1 0}$ & Papanasam & 1983 & 1993 & 1983 & 1979 & 1991 & 1982 & 1983 & 1979 & 1979 & 1980 & 1981 & 1979 \\
\hline $\mathbf{1 1}$ & Sankarankoil & - & - & - & - & - & - & - & - & - & - & - & - \\
\hline $\mathbf{1 2}$ & Shenkottai & 1993 & - & - & - & - & - & - & - & - & - & - & - \\
\hline $\mathbf{1 3}$ & Sivagiri & - & - & - & - & - & - & - & - & - & - & - & - \\
\hline $\mathbf{1 4}$ & Tirunelveli & - & - & - & - & - & - & - & - & - & 1993 & - & - \\
\hline
\end{tabular}


From Table 1, it can be observed that the stations in the western part of the catchment had a step-up change in the late seventies and early eighties. This can especially be observed in the Papanasam (step-up change in all 12 months) and Dam Camp (step-up change in 10 months) stations. Also observed is that the month of January had a step-up change for most of the stations (10 out of 14 stations).

\subsection{Trend analysis results}

The results of the MK test based trend analysis are presented in Table 2, where the MK $Z$-value have been shown. The statistically significant Z-values are shaded in this table.

Table 2. Statistically significant trends for individual months (shaded MK Z-values are statistically significant)

\begin{tabular}{|c|c|c|c|c|c|c|c|c|c|c|c|c|}
\hline Station name & Jan & Feb & Mar & Apr & May & Jun & Jul & Aug & Sep & Oct & Nov & Dec \\
\hline Ambasamudram & -0.60 & +0.64 & -0.98 & +0.08 & -1.53 & +0.78 & -0.75 & +0.26 & -0.60 & +1.85 & -0.73 & +0.05 \\
\hline Ayikudi & -0.90 & +0.41 & +0.53 & -1.67 & -0.42 & -1.40 & -1.31 & -0.38 & -0.61 & -1.05 & -0.76 & -0.58 \\
\hline Cheranmadevi & 0.0 & +0.58 & +0.69 & +1.59 & +1.85 & +1.60 & +1.71 & -0.74 & +0.80 & +1.94 & +2.55 & +1.60 \\
\hline Dam Camp & +0.61 & +0.82 & +0.78 & +0.70 & +1.55 & +0.28 & +0.95 & -0.05 & +1.67 & +0.48 & +0.64 & +0.19 \\
\hline Kayathar & 0.00 & -0.25 & +0.66 & +0.50 & -1.12 & 0.00 & -0.26 & +0.58 & +0.33 & +1.24 & +0.93 & -0.71 \\
\hline Kovilpatti & +0.07 & +1.37 & -1.37 & -0.05 & -1.23 & -0.62 & -0.94 & -1.51 & -0.42 & -0.17 & -0.21 & -1.19 \\
\hline Manimuthar & +0.82 & -0.44 & -1.35 & -0.39 & -0.97 & -1.82 & -0.87 & -1.13 & +0.45 & -0.19 & 0.0 & -1.10 \\
\hline Nanguneri & 0.00 & +0.60 & -0.08 & -0.60 & -0.23 & +1.05 & -0.96 & -0.55 & -2.51 & -0.71 & -0.10 & -1.44 \\
\hline Palayamkottai & -0.18 & -0.21 & -0.30 & +0.37 & +1.69 & +0.37 & +1.03 & +0.25 & -2.19 & -1.26 & +0.32 & -1.42 \\
\hline Papanasam & +0.37 & +1.11 & -0.37 & 0.00 & +0.62 & +1.43 & +1.51 & -0.22 & +2.08 & +1.08 & +1.84 & +1.38 \\
\hline Sankarankoil & +0.87 & -0.33 & -0.03 & +1.08 & -0.53 & +1.21 & +0.98 & +0.16 & -0.42 & +0.64 & +0.37 & -0.69 \\
\hline Shenkottai & -0.37 & +0.62 & -2.05 & +0.50 & +1.17 & +1.21 & -0.28 & -1.85 & -1.08 & +1.96 & +0.57 & -0.98 \\
\hline Sivagiri & +1.39 & +1.49 & -0.94 & +0.21 & -0.55 & -0.50 & -0.73 & -0.73 & -0.46 & +0.60 & 0.00 & 0.00 \\
\hline Tirunelveli & -0.14 & -0.08 & -1.17 & -1.10 & +0.07 & -0.76 & -1.39 & -0.10 & -1.01 & -1.85 & -1.05 & -1.98 \\
\hline
\end{tabular}

The trends results are also presented spatially in Figure 2 to analyze the spatial distribution of the trends. It can be seen that increasing trends are observed at 3 stations, which are Dam Camp (11 months), Papanasam (9 months) and Cheranmadevi (10 months). This is encouraging for the farmers and irrigators in the basin because 2 of these stations are located in the catchment area of the two major reservoirs in the basin.

It can also be observed that decreasing trends are seen in Tirunelveli (11 months), Manimuthar (9 months), Nanguneri (9 months), Kovilpatti (10 months) and Ayyikudi (10 months). Most of these stations are located in the central part of the river basin. 

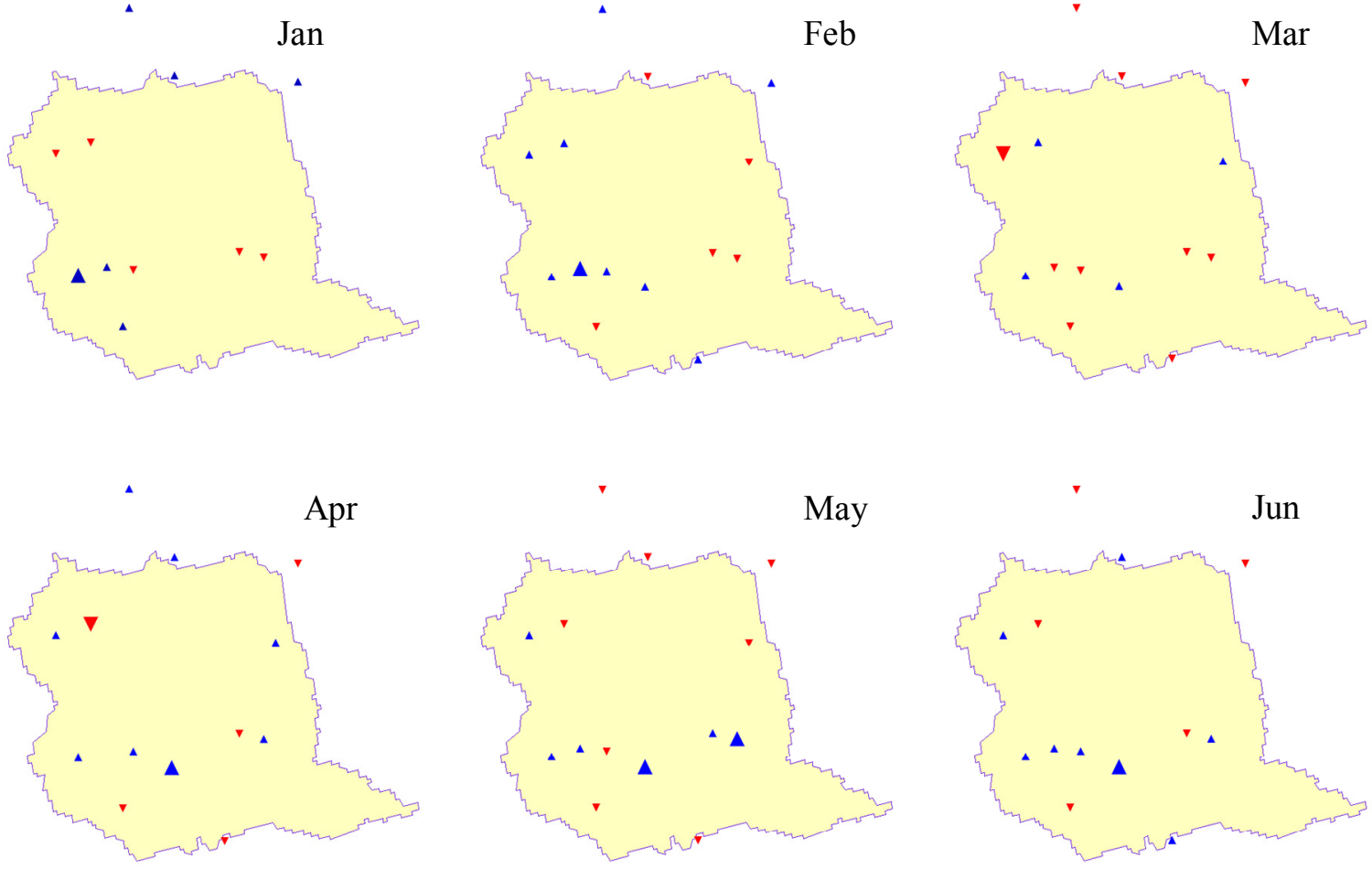

Jul

Aug

Sep
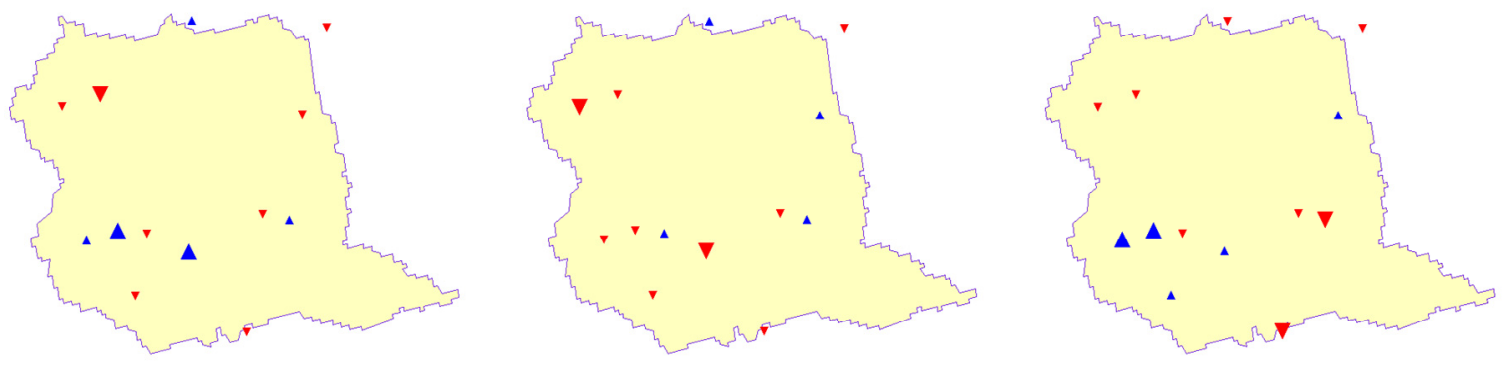

Oct
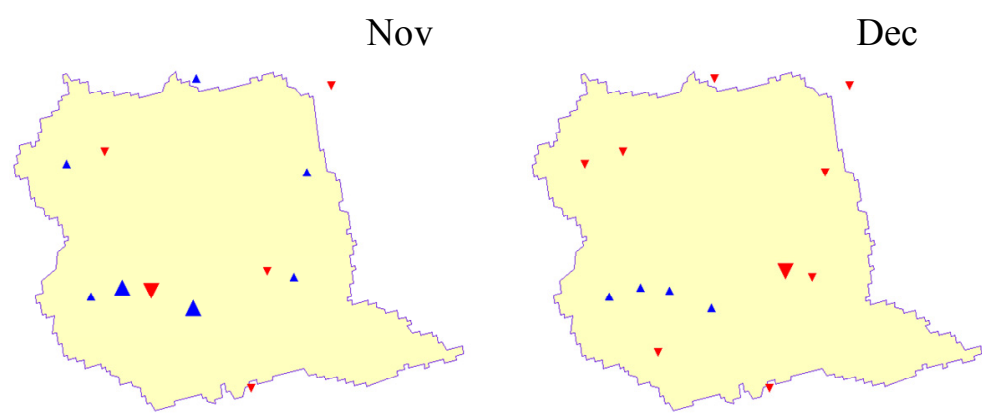

$\Delta$ Increasing trend (statistically significant)

- Increasing trend

$\checkmark$ Decreasing trend

Figure 2. Spatial distribution of monthly rainfall trends 


\section{CONCLUSIONS}

Several studies have been carried out at the national and global scale throughout the world to reveal the climate change impacts on hydro-climatic variables. Some recent studies have also suggested that any analysis of hydro-climatic variables should be done at the local scale rather than at a large or global scale. This is because, although climate change is a global phenomenon, the trends and their impacts may be different from one location to the other. However, no rainfall trend studies were found specific to the Tamarabarani River basin, which is one of the most important water resources basins in southern Tamil Nadu, India.

In this study, a spatio-temporal rainfall trend analysis for monthly rainfall was preformed using the widely used Mann-Kendall test. Monthly rainfall data ranging from 1971 to 2000 at 14 rain gauge stations within the Tamarabarani River basin were used for this analysis. It was observed that the western part of the catchment experienced increasing trends, which were after a step-up change in the early 1980s. It is observed that the central and northeastern part of the catchment had decreasing trends in rainfalls. These decreasing trends could exacerbate the problem of water scarcity in select pockets of the district due to over-exploitation of the surface and groundwater resources. The regions with decreasing trend would need special attention as over exploitation of the water resources in these regions need to be restricted to conserve water for future use.

\section{ACKNOWLEDGMENTS}

The authors would like to acknowledge the use of TREND software, which is one of the tools available in the ewater toolkit developed through the eWater Cooperative Research Centre (eWater CRC).

\section{REFERENCES}

Barua, S., Muttil, N., Ng, A.W.M. and Perera, B.J.C. (2013). Rainfall trend and its implications for water resource management within the Yarra River catchment, Australia. Hydrological Processes, 27(12), 17271738.

Chowdhury R.K. and Beecham S. (2010). Australian rainfall trends and their relation to the southern oscillation index. Hydrological Processes, 24 (4), 504-514.

French, M.N., Krajewski, W.F. and Cuykendall, R.R. (1992). Rainfall forecasting in space and time using a neural network. Journal of Hydrology, 137, 1-31.

Hirsch, R.M., Helsel D.R., Cohn T.A. and Gilroy, E.J. (1993). Statistical analysis of hydrologic data. Handbook of Hydrology, 17, 11-55.

Mann H.B. (1945). Nonparametric tests against trend. Econometrica, 13(3), 245-259.

Sharma R.H. and Shakya N.M. (2006). Hydrological changes and its impact on water resources of Bagmati watershed, Nepal. Journal of Hydrology, 327 (3-4), 315-322.

Yilmaz, A.G. and Perera, B.J.C. (2013). Extreme Rainfall Non-Stationarity Investigation and IntensityFrequency-Duration Relationship. Journal of Hydrologic Engineering, 10.1061/(ASCE)HE.19435584.0000878 (online July 8, 2013).

Yilmaz, A.G., Imteaz, M.A., Gato-Trinidad, S. \& Hossain, I. (2010). Climate Change Finger Prints in Mountainous Upper Euphrates Basin, International Journal of Civil and Environmental Engineering, 3(1), $13-21$. 